\title{
CONTEMPORARY TRENDS OF TRAINING AND COOPERATIVE EDUCATION DEVELOPMENT
}

\author{
Wareeya Khlungsaeng \\ Nathkorn Kumpetch \\ Suan Sunandha Rajabhat University, Bangkok, Thailand
}

The research aims: 1) To study the attitudes of students which are affecting the process of training; and 2) To outline the process of training experience in cooperative education. This research is a descriptive research study with the sample group of Bachelor students, all being in their 3rd year at the College of Innovation and Management, Suan Sunandha Rajabhat University in one of the 3 programs and 5 majors. The tool used for analysis of the questionnaire was based on Mean values and Standard Deviation. The research results revealed the following attitudes of the respondents: cooperative with user service $\left(x_{x=}\right.$ 4.28$, S.D. $=0.75)$ received the highest satisfaction rank; receiving new information demonstrated high satisfaction $\left(x_{x}=4.20\right.$, S.D. $\left.=0.68\right)$ and service quality also got quite high assessments $\left(x_{x}=4.04\right.$, S.D. $\left.=0.75\right)$. In short, this means that the attitude of students who were satisfied matched their demand in the process of cooperative education at the College of Innovation and Management, Suan Sunandha Rajabhat University. Additionally to that, the author of this article provides own recommendations on how to boost learning efficiency even further.

Keywords: cooperative education; attitude of students; Bangkok; Thailand.

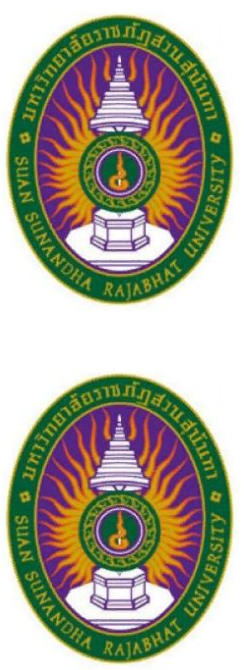

\section{Wareeya Khlungsaeng}

Lecturer in College of Innovations and Management, Suan Sunandha Rajabhat University, Bangkok, Thailand

Science interests: professional training, staff development, innovations in education

E-mail: wareeya.kh@ssru.ac.th

\section{Nathkorn Kumpetch}

Lecturer in College of Innovations and Management, Suan Sunandha Rajabhat University, Bangkok, Thailand

Science interests: personal development, professional trainings, internet education

E-mail: nathkorn.ku@ssru.ac.th 


\section{CONTEMPORARY TRENDS OF TRAINING AND COOPERATIVE}

\section{Introduction}

The key mission of the College of Innovation and Management, Suan Sunandha Rajabhat University is teaching and learning at undergraduate and graduate levels. In this context, all staff of the College have the mission to service and support teaching and research for both teachers and students.

In the $2^{\text {nd }}$ semester of the $3^{\text {rd }}$ year all students of this College are expected to practice cooperative education which assumes getting practical professional education and trying to apply professional theoretical knowledge in its practical application in real-life situations. Various institutions, both government and private ones, are involved in this process providing some sort of testing rooms. Such experiments, combining professional education and real-life situations, can assist the students who already have profound theoretical knowledge but need real experience for further professional enhancement.

Cooperative education is the study format focusing primarily on working practice. This model integrates education with students' real practice in organizations, while the latter is supposed to last for no less than 16 weeks. Organizations involved in this form of education are expected to arrange learning and teaching in the full time mode. Students become temporary similar to officers/employees (meaning, this is NOT an internship). cooperative education student may get the salary, welfare benefits and/or other appropriate compensation from the organization involved.

In this process overall, academic department (as the key service provider) is responsible for students' cooperative education since it is issuing the original official document (the letter of request for assistance and the letter sending to practice cooperative education). These documents describe how well the students are prepared for cooperative education. The following things are mentioned, inter alia: English language proficiency, key personality traits, writing skills, working etiquette etc.

Therefore, in this research the author is trying to demonstrate the important aspects of the attitudes of students affiliated to the College of Innovation and Management regarding their cooperative education procedures. Results and conclusions of this study are aimed to improve the existing workflow, making it more systematic and enabling it demonstrate higher efficiency while meeting organizational targets.

\section{Objectives:}

- To study the attitudes among the students at the College of Innovation and Management towards cooperative education process;

- To be able to integrate the cooperative education experience into the operation efficiency improvement.

\section{Literature review}

\section{Cooperative Education Concept}

Cooperative education is the study system focused on establishing learning and teaching within a workplace. The real practice of socializing and getting direct experience within a workplace in the course of working integrated learning (WIL) is proved to boost skills' development among students.

Professor Vijit Srisaarn, who has been among the first people to talk about cooperative education system in Thailand (namely, at Sunaree University of Technology back in 1993), 
suggested cooperative education and a career development project coining the notion "cooperative education" which was back then understood as "a joint study between university and an establishment to get the learning process according to academic standards, professional standards and aligning with the labor market requirements".

Cooperative education and career development project at Suranaree University of Technology (2002) has the following specific features and steps:

1. Student preparation

cooperative education means that a student is joining a project so that to get some real experience from business operations while serving as a temporary officer for about 16 weeks. The students, at this, have sufficient academic basic and performance abilities. Moreover, they have demonstrated themselves as persons of good behavior and maturity. And overall, they demonstrate preparation for going to work.

2. University preparation

University is expected to establish direct contact with an institution responsible for further cooperative education. The university is also supposed to assign a teacher consultant responsible for orientation and later for evaluation of all students engaged in cooperative education. These consultants are also supposed to follow certain policies regarding both students and their employees.

3. University center preparation

University is also expected to establish a certain structural unit which will be responsible for supporting cooperative education projects, strictly following the philosophy of cooperative education, no less strictly following its results and also assigning coaches for both job trainings and further students' evaluation.

4. Performance \& qualifications

Students are allowed to start working at an organization which is in direct relation with their key subject of studies. Thus, the role and responsibility will be more or less known in advance. For all passed working hours, they are expected to provide an academic report. At the same time, they are also expected to follow personal management regulations, just as all regular employees, and these regulations may concern many things, from standard working hours to dress code in an organization.

\section{The concept and the theory of attitude}

Generally speaking, attitude means the inclination when behaving aligns with satisfaction or dissatisfaction with something or, in other words, expressing inner feeling of being satisfied or dissatisfied with something. The attitude cannot be observed directly but, in simple terms, it means what that the person is saying or doing.

Seri Wongmonta (1999:106) provided the definition of attitude as person's feeling to another person, thing or way of thinking. The attitude is something leading people to change their behavior or at least their readiness to act so. Positive attitude usually leads to positive acts; negative attitude causes negative acts.

Thongchai Santiwong (1991:161-162) understood attitude as the story that happened to personality, it is concept arrangement, belief, habit or a relatively permanent attraction to something.

From all of the above concepts and theories, attitude is the inner feeling of personality to something, which can be both positive and negative, and which includes the ability to change behavior, thoughts and feelings. 


\section{CONTEMPORARY TRENDS OF TRAINING AND COOPERATIVE}

\section{The concept of satisfaction}

Rachwale Worawut (2005) put forward the idea that satisfaction is part of human behavior which is an attempt to eliminate stress, anxiety or other unbalanced conditions whenever the human could eliminate such things, so that later the human is satisfied with the things in demand. The definition of satisfaction, according to the philosophical dictionary, is the feeling of the experience gained from accessing something or it is an inner, personal feeling of being happy or being pleased with the response to own demand for missing things or a certain unbalance.

Siripong Pheutipan and Payut Wutthirong (2004, 57-58) summarized satisfaction in its following aspects:

1. Satisfaction is the comparison of feelings and expectations;

2. Satisfaction is the comparison of feelings and motivation;

3. Satisfaction is the comparison of feeling or attitude and what has actually happened;

4. Satisfaction is the comparison of experience with expectation.

The Dictionary of the Royal Academy (1999) provided the definition or satisfaction which means love, like, pleased and gratified, or all of it.

Taneeya Panyakeaw (1998) provided the definition of satisfaction directly in relation to one's job. The following factors may lead satisfaction with job done: success, honor, job character, responsibility and progressivity. Noteworthy, the opposite of these factors may cause dissatisfaction with the job. In simple terms, if a job is progressive, relatively challenging (but not too much), may bring success and honor to employees, the latter will be eventually satisfied and thus have motivation to work more.

Siriwan Serirat (1991: 18) stated that satisfaction of customers is the feeling from being serviced consists of:

1. Satisfaction by convenience provided by the service;

2. Satisfaction by coordination with the service provider;

3. Satisfaction with hospitality and attention of the service provider;

4. Satisfaction with news and other information received;

5. Satisfaction with usability of the service and with the service fee.

\section{Literature review}

Tayanit Mitrpeang and Jutamas Dononbao (2013) studied education management in cooperative education, and their population consisted of the executives from the Faculty of Art and Architecture at Rajamangala University of Technology Lanna, Payap campus, Chiangmai, including supervisors of the departments and other professionals. Analysis of the obtained information has helped understanding the opinions of the local executives concerning the policies supporting cooperative education. The performance of cooperative education, on average, was assessed as 3.63 which is relatively high. Other parameters got medium-level ranks, including: the intention to join cooperative education, personally knowing somebody related to cooperative education, understanding how cooperative education actually works and being able to coach students in the course of cooperative education. The study results show that the faculty executives were focused on cooperative education performance primarily because it was on the program of activities and also because 
this was opening more opportunities for the students to practise skills relevant for professional work.

Atcharaporn Chotipheu (2012) studied the cooperative education management model on the case of Sripatum University. Their research had the objective to study the cooperative education situation at this university, dividing it into 3 processes: first, studying the cooperative education situation at Sripatum University according to published documents and electronic document (e-docs); second, considering the cooperative education management model developed at Sripatum University and using a questionnaire for this, asking 17 specialists of cooperative education and then applying Delphi technique for analysis; and third was the inspection of the feasibility of applying the cooperative education management model at Sripatum University, it involved 50 people in total.

\section{Methodology}

The researcher used questionnaire to collect data from the population. The questionnaire was created by the researcher according to the information from textbooks and other literature. The questionnaire consisted of two parts:

Part 1. It covers the social status of the respondents, including gender, education etc. These were closed questions mostly.

Part 2. This part contains questions about the attitudes of students to the process before the cooperative education training, during cooperative education training and then after it. These were also closed questions. Likert scale was used, and all the respondents could select only one answer.

\section{Research Results}

54 people (or 54\%) of our respondents were male, while 46 people (or $46 \%$ ) were female.

The respondents were all students in: Information Technology Management, Quality Management, Human Capital and Organization Management, Information Technology and Communication for Marketing, Political Science. 20 students for each of these subjects.

The attitude of students affecting the process before cooperative education has been found to be of high level $(\bar{x}=4.18$, S.D. $=0.11)$. The number one was the coordination of cooperative education between students and the college, it has achieved the highest level $(\bar{x}=$ 4.28, S.D. $=0.75)$. The second goes the coordination of sending the students to a specific institutions, its level was not that lower $(\bar{x}=4.21$, S.D. $=0.69)$. Coordination of cooperative education between students and college turns out to be also at high level $(\bar{x}=4.20$, S.D. $=$ $0.68)$, knowledge and understanding about cooperative education being at almost the same high level $(\bar{x}=4.19$, S.D. $=0.75)$. Finally, cooperative education orientation projects is also found to be at high level ( $x=4.04$, S.D. $=0.75)$.

The attitude of students affecting the process of cooperative education performance is found to be at the highest level $(\bar{x}=4.29$, S.D. $=0.09)$. If the overall attitude is considered on a question by question basis, the highest level of all questions gets the orientation of teacher 


\section{CONTEMPORARY TRENDS OF TRAINING AND COOPERATIVE}

as the benefit for the institution $(\bar{x}=4.34$, S.D. $=0.61)$. Second goes the advice for students during their work $(\bar{x}=4.31$, S.D. $=0.67)$. It is followed by student operational performance during cooperative education $(\bar{x}=4.29$, S.D. $=0.69)$ and then goes student orientation period $(\bar{x}=4.27$, S.D. $=0.73)$. The closing one is the number of times that the teacher came to orientation $(\bar{x}=4.24$, S.D. $=0.77)$.

The attitude affecting the process after cooperative education performance is also found to be quite high $(\bar{x}=4.29$, S.D. $=0.26)$. If to consider each question separately, the results would be in the following order: first information about the activity after coming back from cooperative education $(\bar{x}=4.30$, S.D. $=0.62)$, reporting process after finished cooperative education $(\bar{x}=4.27$, S.D. $=0.69)$, appropriate evaluation of the performance $(\bar{x}=4.25$, S.D. $=0.69)$.

\section{Analysis of the respondents' opinions overall}

Overall, opinions of the respondents can be divided into 3 sectors as follows:

The attitude of students affecting the process before the actual cooperative education is found to be at the high level $(\bar{x}=4.18$, S.D. $=0.11)$. If considered on a question by question basis, the first goes the coordination of cooperative education between students and college as it has the highest level $(\bar{x}=4.28$, S.D. $=0.75)$. Then goes coordination while sending students to an institution which also has quite high level $(\bar{x}=4.21$, S.D. $=\underline{0}$.69), knowledge and understanding of cooperative education also got quite high scores $(x=4.19$, S.D. $=$ $0.75)$, followed by cooperative education orientation project with $(\bar{x}=4.04$, S.D. $=0.75)$.

Processes during and after cooperative education got the highest scores in terms of students' attitudes, as compared to the processes of preparation before cooperative education. If considered for each subject separately, the results will look as follows:

\section{Processes immediately during cooperative education training:}

Information Technologies for Communications and Marketing students were satisfied the most. They were followed by the students majoring in Information Technology System Management for Business (4.32), Political Science (4.30), Human Capital and Organization (4.28) and finally Quality Management (4.18).

\section{Processes after cooperative education:}

The highest score (4.41) was obtained from the students majoring in Information Technologies and Communication for Marketing. Then go Information Technology System Management for Business (4.35), Human Capital and Organization (4.24), Political Science (4.23) and Quality Management (4.22).

\section{Processes before cooperative education:}

Again, the highest satisfaction score was demonstrated by the students majoring in Information Technologies and Communication for Marketing (4.27). They were followed by 
Quality Management students (4.18), Human Capital and Organization students (4.16) and Information Technology System Management for Business (4.12).

\section{Conclusions stemming from the research results:}

The researcher would like to emphasize the following research result utility:

1. Cooperative education management process is highly important for all the service users since it is really able to improve the efficiency of cooperative education.

2. Attitudes of service users are always affecting the cooperative education management process. Thus, good attitude makes service provider find resources to improve the process.

\section{Acknowledgement}

The research was supported under the scholarship provided by the Research and Development Institution, Suan Sunandha Rajabhat University, Bangkok, Thailand.

The researcher thanks the dean and the dean deputy, all teachers, officers and also undergraduate students at the College of Innovation and Management, namely, future Bachelors of Business Administration Program, majoring in Quality Management, Information Technology Management for Business, Human Capital and Organization, Bachelors of Political Science Program and also Bachelors of Sciences Program, majoring in Information Technologies and Communication for Marketing, as all of them became valuable sources of the collected data for this research.

\section{References:}

Chotipeu, A. (2012). Cooperative Education Management Model Development. Sriprathom University.

Mitrpeang, T. \& Dononbao, J. (2013). Feasibility study of cooperative education management at the Faculty of Art and Architecture. Rajamangala University of Technology Lanna.

Reusrichun, S. (2011). Attitude, Satisfaction View and Consumer Behavior using the Fulolsol Field Service. Bangkok Srinakharinwirot University.

Saramanus, S., Chuntanatap, V. \& Singhadham, P. (2014). Achievement Evaluation of Cooperative Education Project. Rajamangala University of Technology Phra Nakhon.

Sawasdipak, S. (2003). Attitude of customers affecting the business organization using social marketing policy. Burapha University.

Techpahapong, S. (2015). Cooperative education management for university in case of major business and vocational education. Faculty of Education, Chulalongkorn University.

Paper submitted

Paper accepted for publishing

Paper published online
19 April 2019

28 June 2019

08 August 2019 